\title{
Peranan Dinasti Abbasiyah Terhadap Peradaban Dunia
}

\author{
Iqbal \\ UIN Alauddin Makasar \\ Iqbalhayoung93@gmail.com
}

\begin{abstract}
Abbasiyah empire is which one empire in Islam. In History, Abbasiyah empire is top empire, so we called it as "The Golden Age of Islam". This empire exist when Umayyah empire had fallen in Damaskus. Umayyah's generation (Abdu al-Rahman alDakhil) escape from Abbasiyah empire and went to Andalusia. And automatically Abbasiyah empire exist in Damaskus. After Abbasiyah could controlled moslems in Damaskus, they changed governance center to Baghdad. In Baghdad, they developed sciences. They translated manuscript foreign languages to Arabic. Beside it, Abu Ja'far al-Manshur was building Baitul Hikmah as a library and center of sciences development.
\end{abstract}

Keyword: Abbasiyah Empire, World Civilization

\section{A. Pendahuluan}

Islam sebagai agama yang benar, tentu membawa ajaran yang sesuai dengan realitas serta prinsip kemanusiaan yang menjunjung tinggi harkat, martabat, serta derajat umat manusia. Islam datang membawa cahaya gemerlapan di tengah-tengah umat manusia yang berada dalam kegelapan. Islam datang membawa petunjuk, agar umat manusia selamat dunia maupun akhirat. Sejarah telah membuktikan bahwa Islam pernah menjadi adikuasa di bumi ini. Dengan berdasarkan Alquran dan al-Sunnah maka Islam telah membuktikan kebenarannya, yang membawa umat manusia dari tak beradab menjadi manusia yang memiliki peradaban tinggi. Rasulullah sebagai peletak dasar peradaban Islam telah memberikan contoh yang amat jelas antara kebenaran dan kebatilan. Rasulullah bahkan telah memberikan contoh kepemimpinan yang baik kepada segenap umat manusia. Alquran dan sunnah merupakan dua dasar fundamental penegak peradaban Islam. Keduanya merupakan asas bagi peradaban Islam. ${ }^{1}$ Sejarah telah membuktikan eksistensi umat Islam di masa lalu, yang telah membangun peradaban yang tidak ada duanya, bahkan Eropa sendiri jauh

${ }^{1}$ Raghib al-Sirjani, Madza Qaddamal lil 'Alam Ishaamatu al-Muslimin fi al-Hadharah alInsaniyah, terj. IKAPI, Sumbangan Peradaban Islam pada Dunia (Jakarta: Pustaka al-Kautsar, 2011), h. 39. 
tertinggal pada zaman tersebut sehingga disebut "The Dark Age" (Zaman Kegelapan), sementara peradaban Islam disebut "The Golden Age" (Zaman Keemasan).

Peradaban Islam mencapai puncaknya pada Dinasti Abbasiyah. Dinasti Abbasiyah merupakan Dinasti yang berkuasa setelah Dinasti Umayyah di Damaskus runtuh. Setelah keruntuhan Dinasti Umayyah, Dinasti Abbasiyah membangun peradaban Islam atas asas ilmu pengetahuan. Selain itu, Dinasti Abbasiyah pernah menjadikan aliran Muktazilah sebagai aliran resmi negara. Aliran ini didukung oleh Khalifah al-Makmun anak dari Harun al-Rasyid. ${ }^{2}$ Hal ini menimbulkan pengkajian Alquran secara rasional, karena Muktazilah sendiri mengkaji Alquran sesuai dengan logika. Hal ini dapat dianggap bahwa ternyata Post Modernisme telah ada jauh sebelum Bangsa Eropa bangkit. Jika demikian, berarti Dinasti Abbasiyah memiliki peranan penting dalam perkembangan peradaban dunia, oleh karena para ilmuwan banyak muncul pada era Dinasti Abbasiyah. Dinasti Abbasiyah sebagai pesaing Dinasti Umayyah tentu ingin membangun peradaban Islam melebihi Dinasti Umayyah. Sejarah persaingan di antara keduanya sebetulnya telah dimulai sejak dahulu kala, yakni dimulai dari persaingan Bani Hasyim dan Bani Umayyah. Persaingan antara Bani Hasyim dengan Bani Umayyah itu sudah berjalan lebih dari seratus tahun sebelum Nabi lahir. ${ }^{3}$ Padahal mereka merupakan sebuah keluarga besar yang seharusnya tak terpisahkan. Bahkan di antara keduanya terdapat hubungan pernikahan, seperti Utsman Bin Affan yang menikah dengan Ruqayyah putri Rasulullah. ${ }^{4}$ Meskipun demikian, kedua Dinasti tersebut telah membuktikan bahwa mereka mampu membangun peradaban Islam di atas persaingan di antara keduanya. Bahkan Dinasti Abbasiyah telah membangun peradaban yang gemilang di bawah pimpinan Harun al-Rasyid. Pepatah mengatakan sepintar-pintarnya tupai

${ }^{2}$ Ahmad Amin, Dhuha al-Islam III,(Cairo Mesir, al-Nahdhah al-Mishriyah, 1966), h. 8.

${ }^{3}$ Muhammad Husain Haekal, Utsman Bin Affan, terj. Ali Audah, Usman Bin Affan (Bogor: Pustaka Litera Antarnusa, 2010), h. 9.

${ }^{4}$ Ali Muhammad al-Shalabi, Muawiyah Ibnu Abi Sufyan, terj. Izzuddin Karimi, Muawiyah Bin Abu Sufyan (Jakarta: Darul Haq, 2012), h. 12. 
melompat, pasti akan jatuh juga. Hal ini pun berlaku bagi Dinasti Abbasiyah. Meskipun Dinasti Abbasiyah merupakan puncak peradaban, Dinasti Abbasiyah pun mengalami kemunduran dan kehancuran. Secara rasio, seseorang yang telah mencapai puncak gunung, tentu suatu hari akan turun ke kaki gunung, karena ia tak dapat lagi melanjutkan perjalanan, karena tak ada lagi tempat di atas puncak gunung. Demikian pula dengan Dinasti Abbasiyah. Sebuah Dinasti yang mencapai puncaknya tentu secara perlahan akan mengalami kemunduran dan kehancuran.

\section{B. Kajian Pustaka}

Artikel ini ditulis dengan merujuk pada beberapa buku. Salah satu buku yang digunakan adalah buku tulisan Ali Muhammad al-Syalabi yang berjudul Bangkit dan Runtuhnya Daulah Bani Saljuk. Buku ini membahas tentang Daulah Bani Saljuk mulai dari awal berdirinya, pemerintahannya, kemajuannya serta pormasalahan yang timbul pada masanya samapi keruntuhannya. Kemudian buku tulisan Ahmad al-Usairy yang berjudul Sejarah Islam (Sejarah Nabi Adam hingga Abad XX). Buku ini membahas pada salah satu babnya tentang pemerintahan Dinasti Abbasiyah serta permasalahannya hingga keruntuhannya. Selain itu buku yang digunakan juga adalah buku tulisan Badri Yatim yang berjudul Sejarah Peradaban Islam yang salah satu babnya membahas tentang Dinasti Bani Abbas, mulai dari pemerintahan, kemajuan dan keruntuhannya.

\section{Metode Penelitian}

Dalam rangka melakukan penelitian, penulis melakukan suatu pendekatan yang sesuai dengan studi dalam penyusunan tesis ini adalah pendekatan historis atau pendekatan sejarah, hal ini sangat relevan dengan judul penelitian. Pendekatan historis atau pendekatan sejarah merupakan salah satu pendekatan yang dapat digunakan dalam melakukan penelitian tentang objek sejarah, agar mampu mengungkapkan banyak dimensi dari peristiwa tersebut. Mengenai pengumpulan data penulis melakukannya dalam bentuk library research, yakni mengumpulkan beberapa literatur yang berkaitan dengan masalah-masalah yang akan dibahas baik buku dan majalah, maupun tulisan lain, yang akan dijadikan bahan acuan dalam penulisan ini. Penulis membaca beberapa buku yang 
berhubungan dengan objek kajian, tentu saja yang ada hubungan dengan pembahasan.

\section{Pembahasan}

Sejarah berdirinya Dinasti Abbasiyah tentu tidak terlepas dari sejarah kemunduran Dinasti Umayyah. Sejarah kemunduran Dinasti Umayyah berawal dari bobroknya akhlak para pemimpin Dinasti Bani Umayyah. Empat pengganti khalifah setelah Muawiyah dan Abd. Malik kecuali Marwan yang menjadi khalifah terakhir terbukti tidak cakap atau bisa dikatakan tidak bermoral. Bahkan para khalifah sebelum Hisyam pun, yang dimulai oleh Yazid I lebih suka berburu, pesta minum, tenggelam dalam alunan musik dan puisi ketimbang membaca Alquran atau mengurus persoalan Negara. Berpoya-poya dalam kemewahan,oleh karena meningkatnya kekayaan dan melimpahnya budak menjadi fenomena umum. Bahkan keluarga khalifah tidak lagi berdarah Arab murni, Yazid III (744 M.) adalah khalifah pertama yang lahir dari seorang budak. Perilaku buruk kelas penguasa hanyalah gambaran kecil dari keburukan moral yang bersifat umum. ${ }^{5}$

Selain itu, pada saat Hisyam Bin Abdul Malik memerintah pada tahun 105-125 H./723-742 M. ${ }^{6}$ Daulah Islam telah mengalami kemerosotan dan melemah. Hal ini terjadi karena fanatisme antara orang-orang Arab Selatan dan Arab Utara, secara khusus Khurasan. ${ }^{7}$ Apalagi setelah Hisyam wafat pada tahun 125 H./742 M., penguasa setelah itu yakni Walid Bin Yazid Bin Abdul Malik dikenal sebagai sosok yang menuruti hawa nafsunya dan tindakan-tindakan yang tidak pantas, sehingga banyak manusia yang jengkel terhadapnya. Dalam buku Imam al-Suyuthi bahkan dijelaskan bahwa ia merupakan khalifah yang fasik, peminum khamar, dan banyak merusak aturan-aturan Allah. ${ }^{8}$ Oleh karena itu,

${ }^{5}$ Philip K. Hitti, History of the Arabs; From the Earliest Times to the Present, terj. R. Cecep Lukman Yasin dan Dedi Slamet Riyadi, History of the Arabs (Jakarta: PT. Serambi Ilmu Semesta, 2010), h. 348.

${ }^{6}$ Ahmad al-Usairy, Al-Tarikh al-Islami, terj. Samson Rahman, Sejarah Islam (Jakarta: Akbar Media, 2012), h. 207.

${ }^{7}$ Ahmad al-Usairy, Al-Tarikh al-Islami, terj. Samson Rahman, Sejarah Islam ., h. 209.

${ }^{8}$ Al-Suyuthi, Tarikh Khulafa', terj. Samson Rahman, Tarikh Khulafa': Sejarah Para Penguasa Islam (Jakarta : Pustaka al-Kautsar, 2011), h. 297. 
secara diam-diam masyarakat membaiat sepupunya Yazid Bin Walid yang dikenal sebagai sosok yang shaleh. ${ }^{9}$ Dan Walid pun terbunuh pada bulan Jumadil akhir tahun 126 H. $^{10}$ Pada saat Yazid berkuasa, ternyata masalah tidak juga terselesaikan. Gejolak dan pemberontakan terjadi di mana-mana. Tidak ada kata tunggal di kalangan Bani Marwan. Orang-orang Hismh memberontak, disusul kemudian oleh penduduk Palestina. Meskipun pemberontakan ini berhasil diredam ternyata muncul lagi konflik baru antara Qaisiyyah dan Yamaniyah terutama di Khurasan.

Melihat keadaan semakin kacau, keluarga Abbas pun memanfaatkan situasi dan bergabung dengan pendukung Ali dengan menekankan hak keluarga Hasyim. Dengan memanfaatkan kekecewaan publik dan menampilkan diri sebagai pembela sejati agama Islam, para keturunan Abbas segera menjadi pemimpin gerakan anti Umayyah. ${ }^{11}$ Seruan dan gerakan untuk membangun pemerintah Bani Abbas semakin santer pada masa itu dengan kufah sebagai sentralnya dan menyebar ke Khurasan. Penyeru utama pembentukan pemerintahan Abbasi adalah Muhammad Bin Ali Abdullah Bin al-Abbas. Ia meninggal pada tahun 124 H./741 M. yang kemudian digantikan oleh anaknya Ibrahim. Pada masa ini muncul gerakan Abu Muslim Khurasani, salah seorang penyeru pendirian pemerintahan Bani Abbasi. ${ }^{12}$ Hal itulah yang terjadi silih berganti pada akhir masa Dinasti Umayyah.

Kejatuhan Dinasti Umayyah semakin dekat ketika terbentuk koalisi antara kekuatan Syiah, Khurasan, dan Abbasiyah, yang dimanfaatkan oleh kelompok terakhir untuk kepentingan mereka sendiri. Koalisi ini dipimpin oleh Abu alAbbas, cicit al-Abbas, paman Nabi. Di bawah kepemimpinannya, Islam revolusioner bangkit menentang tatanan yang ada dengan menawarkan gagasan teokrasi, dan janji untuk kembali kepada tatanan ortodoksi. Pada 9 Juni 747M./130 H, pemberontakan dimulai ketika seorang pendukung Abbasiyah Abu

\footnotetext{
${ }^{9}$ Ahmad al-Usairy, Al-Tarikh al-Islami, terj. Samson Rahman, Sejarah Islam, h. 207.

${ }^{10}$ Al-Suyuthi, Tarikh Khulafa', terj. Samson Rahman, Tarikh Khulafa': Sejarah Para Penguasa Islam (Jakarta : Pustaka al-Kautsar, 2011), h. 297

${ }^{11}$ Al-Suyuthi, Tarikh Khulafa', terj. Samson Rahman, Tarikh Khulafa' : Sejarah Para Penguasa Islam, h. 297

${ }^{12}$ Ahmad al-Usairy, Al-Tarikh al-Islami, terj. Samson Rahman, Sejarah Islam, h. 208.
} 
Muslim seorang budak Persia yang telah dimerdekakan mengibarkan bendera hitam, yang pada awalnya merupakan warna bendera Muhammad, tapi kini menjadi lambang Abbasiyah.

Gerakan untuk mendirikan pemerintahan Bani Abbasiyah pun semakin kuat. Pada tahun 129 H./ 446 M., mereka memproklamirkan berdirinya pemerintahan Abbasiyah. Namun Marwan menangkap pemimpinnya yang bernama Ibrahim lalu dibunuh. Setelah dibunuh, pucuk gerakan diambil alih oleh saudaranya yang bernama Abul Abbas al-Saffah yang berangkat bersama-sama dengan keluarganya menuju Kufah. Kemudian dia dibaiat sebagai khalifah di Kufah pada tahun 132 H./ 749 M. Bani Abbasiyah berhasil menaklukkan Khurasan dan Irak. Maka terjadilah pertempuran antara pasukan Abbasiyah dan pasukan Marwan Bin Muhammad di Sungai Zab (antara Mosul dan Arbil). Marwan dan pasukannya kalah dalam peperangan yang terjadi pada 131 H./ 748 M. Pasukannya lari ke berbagai penjuru hingga akhirnya dia dibunuh oleh pasukan Bani Abbasiyah pada tahun 132 H./ 749 M. Dengan kematiannya, maka pemerintahan Umayyah hancur dan awal pembentukan Dinasti Abbasiyah. ${ }^{13}$

Dalam perkembangannya Daulah Abbasiyah dibagi menjadi lima periode yakni, Periode Pertama (750 M. - 847 M.), yang para khalifah Abbasiyah berkuasa penuh. Periode Kedua (847 M. - 945 M.) disebut periode pengaruh Turki. Periode Ketiga (945 M. - 1055 M.) pada masa ini daulah Abbasiyah di bawah kekuasaan Bani Buwaihi. Periode Keempat (1055 M.-1194 M.) dalam periode ini ditandai dengan kekuasaan Bani Saljuk atas Daulah Abbasiyah. Periode Kelima (1194 M.-1258 M.) periode ini khalifah Abbasiyah tidak lagi berada di bawah kekuasaan dinasti tertentu, mereka merdeka berkuasa akan tetapi hanya di Baghdad dan sekitarnya. ${ }^{14}$

Pada periode pertama pemerintahan Bani Abbas mencapai masa keemasannya. Secara politis, para khalifah adalah tokoh yang kuat dan merupakan pusat kekuasaan politik dan agama sekaligus. Di sisi lain,

\footnotetext{
${ }^{13}$ Ahmad al-Usairy, Al-Tarikh al-Islami, terj. Samson Rahman, Sejarah Islam, h. 211-212.

${ }^{14}$ Departemen Agama Republik Indonesia, Ensiklopedi Islam I (Jakarta: Ichtiar Baru Van Hoeve, 1997),h. 7-9.
} 
kemakmuran masyarakat mencapai tingkat tertinggi. Periode ini juga berhasil menyiapkan landasan bagi perkembangan filsafat dan ilmu pengetahuan dalam Islam. Namun setelah periode ini berakhir, pemerintahan Bani Abbas mulai menurun dalam bidang politik, meskipun filsafat dan ilmu pengetahuan terus berkembang. Sebenarnya zaman keemasan Bani Abbas telah dimulai sejak pemerintahan Khalifah Abu Ja'far al-Mansur serta pada masa Khalifah al-Mahdi (775-785 M.), akan tetapi popularitas Daulah Abbasiyah mencapai puncaknya pada masa khalifah Harun al-Rashid (786-809 M.) dan putranya al-Ma'mun (813833 M.). Kekayaan banyak dimanfaatkan Harun al-Rashid untuk keperluan sosial. Rumah sakit, lembaga pendidikan dokter dan farmasi didirikan. Pada masanya sudah terdapat paling tidak sekitar 800 orang dokter. Disamping itu, pemandianpemandian umum juga dibangun. Kesejahteraan, sosial, kesehatan, pendidikan, ilmu pengetahuan, dan kebudayaan serta kesusasteraan berada pada zaman keemasannya. Pada masa inilah negara Islam menempatkan dirinya sebagai negara terkuat dan tak tertandingi. Khalifah-khalifah Bani Abbas secara terbuka mempelopori perkembangan ilmu pengetahuan dengan mendatangkan naskahnaskah kuno dari berbagai pusat peradaban sebelumnya untuk kemudian diterjemahkan, diadaptasi dan diterapkan di Dunai Islam. Para ulama' muslim yang ahli dalam berbagai ilmu pengetahuan baik agama maupun non agama juga muncul pada masa ini. Perkembangan pesat peradaban juga didukung oleh kemajuan ekonomi imperium yang menjadi penghubung Dunia Timur dan Barat. Stabilitas politik yang relatif baik terutama pada masa Abbasiyah awal ini juga menjadi pemicu kemajuan peradaban Islam.

Sejarah menyebutkan bahwa puncak zaman keemasan Baghdad terjadi selama masa kekhalifahan Harun al-Rasyid (786-809 M.) Meskipun usianya kurang dari setengah abad, Baghdad pada saat itu muncul menjadi pusat dunia dengan tingkat kemakmuran dan peran internasional yang luar biasa. Baghdad menjadi saingan tunggal bagi Bizantium. Kejayaannya berjalan seiring dengan kemakmuran kerajaan, terutama ibu kotanya. Saat itulah Baghdad menjadi kota 
yang tidak ada bandingannya di sekitar Jazirah Arab. ${ }^{15}$ Istana kerajaan dengan bangunan-bangunan tambahan untuk para harem, pembantu laki-laki dan pejabatpejabat khusus menempati sepertiga Kota Lingkaran itu. Bagian yang paling mengesankan adalah ruang pertemuan yang dilengkapi dengan karpet, gorden dan bantal terbaik dari Timur. ${ }^{16}$

Selain itu, zaman Harun al-Rasyid merupakan zaman kebangkitan intelektual. Gerakan intelektual itu ditandai oleh proyek penerjemahan karyakarya berbahasa Persia, Sansekerta, Suriah, dan Yunani ke bahasa Arab. Dimulai dengan karya mereka sendiri tentang ilmu pengetahuan, filsafat, atau sastra yang tidak terlalu banyak. Orang Arab Islam yang memiliki keingintahuan yang tinggi dan minat belajar yang besar segera menjadi penerima dan pewaris peradaban bangsa-bangsa yang lebih tua dan berbudaya yang mereka taklukkan atau yang mereka temui. ${ }^{17}$ Selain mempelajari dan menyerap ilmu pengetahuan dari bangsa lain, Khalifah Abu Ja'far al-Manshur membangun perpustakaan Baitul Hikmah, salah satu perpustakaan yang amat terkenal dan berkelas dunia. Perpustakaan tersebut mencerminkan peranan ilmu di dunia tanpa dapat diketahui batasannya, dan salah satu perbendaharaan ilmiah yang paling bernilai dalam pemikiran Islam. $^{18}$

Selain itu, budaya India pun turut andil dalam mempengaruhi pembentukan budaya universal Islam Persia, terutama yang menjadi sumber inspirasi pertama dalam bidang mistisisme dan matematika. Sekitar 154 H./771 M., seorang pengembara India memperkenalkan naskah astronomi ke Baghdad yang berjudul Siddhanta (bahasa Arab Sidhind), yang atas perintah al-Manshur kemudian diterjemahkan oleh Muhammad Bin Ibrahim al-Fazari (meninggal antara 796 M.-806 M.), yang kemudian menjadi astronom Islam pertama. Bintang

\footnotetext{
${ }^{15}$ Philip K. Hitti, History of the Arabs; From the Earliest Times to the Present, terj. R. Cecep Lukman Yasin dan Dedi Slamet Riyadi, History of the Arabs, h. 375.

${ }^{16}$ Philip K. Hitti, History of the Arabs; From the Earliest Times to the Present, terj. R. Cecep Lukman Yasin dan Dedi Slamet Riyadi, History of the Arabs, h. 375

${ }^{17}$ Philip K. Hitti, History of the Arabs; From the Earliest Times to the Present, terj. R. Cecep Lukman Yasin dan Dedi Slamet Riyadi, History of the Arabs, h. 381.

${ }^{18}$ Raghib al-Sirjani, Madza Qaddamal lil 'Alam Ishaamatu al-Muslimin fi al-Hadharah al-Insaniyah, terj. IKAPI, Sumbangan Peradaban Islam pada Dunia, h. 239.
} 
memang telah menarik minat orang Arab sejak dulu, tapi mereka baru melakukan kajian ilmiah tentang perbintangan pada masa ini. ${ }^{19}$ Pengembara India itu juga membawa sebuah naskah tentang matematika yang darinya bilangan-bilangan yang di Eropa disebut sebagai bilangan Arab dan yang oleh orang Arab disebut bilangan India (Hindia) yang masuk ke dunia Arab. Belakangan pada abad ke 9 M., orang India juga memberi sumbangan penting terhadap ilmu matematika Arab, yaitu sistem desimal. ${ }^{20}$

Al-Ma'mun, pengganti Harun al-Rasyid, dikenal sebagai khalifah yang sangat cinta kepada ilmu filsafat. Pada masa pemerintahannya, penerjemahan buku-buku asing digalakkan. Untuk menerjemahkan buku-buku Yunani, ia menggaji penerjemah-penerjemah dari golongan Kristen dan penganut agama lain yang ahli, Ia juga banyak mendirikan sekolah, salah satu karya besarnya yang terpenting adalah pembangunan Baitul-Hikmah, pusat penerjemahan yang berfungsi sebagai perguruan tinggi dengan perpustakaan yang besar. Pada masa al-Ma'mun inilah Baghdad mulai menjadi pusat kebudayaan dan ilmu pengetahuan. Permulaan lahirnya ilmu pengetahuan sebenarnya telah lahir pada masa-masa sebelum Dinasti Abbasiyah yang lebih tepat pada masa Yunani kuno, akan tetapi keilmuan-keilmuan ini berkembang pesat pada masa Daulah Abbasiyah. Jika diteliti sebenarnya ilmu telah ada pada permulaan manusia atau lebih tepat pada zaman manusia purba. Pada masa ini manusia telah menemukan besi, tembaga, dan perak untuk berbagai peralatan. Baru setelah itu muncul keilmuan di Yunani. ${ }^{21}$ Dengan pendirian perpustakaan dan akademi. Perpustakaan pada masa itu lebih merupakan sebuah universitas, karena selain terdapat kitabkitab, di sana orang juga dapat membaca, menulis dan berdiskusi. Perkembangan lembaga pendidikan itu mencerminkan terjadinya perkembangan dan kemajuan ilmu pengetahuan. Hal ini sangat ditentukan oleh perkembangan bahasa Arab,

${ }^{19}$ Philip K. Hitti, History of the Arabs; From the Earliest Times to the Present, terj. R. Cecep Lukman Yasin dan Dedi Slamet Riyadi, History of the Arabs, h. 382.

${ }^{20}$ Philip K. Hitti, History of the Arabs; From the Earliest Times to the Present, terj. R. Cecep Lukman Yasin dan Dedi Slamet Riyadi, History of the Arabs, h. 383.

${ }^{21}$ Surajio, Filsafat Ilmu dan Perkembangannya di Indonesia (Jakarta: PT. Bumi Aksara,2010), h. 80. 
baik sebagai bahasa administrasi yang sudah berlaku sejak zaman Bani Umayyah, maupun sebagai bahasa ilmu pengetahuan.

Pada pemerintahan al-Makmun, untuk memfokuskan penerjemahan naskah-naskah asing, maka dibentuk badan penerjemah dan pensyarah serta para penjual kertas untuk menjaga agar naskah kuno itu tidak sampai punah dan dipindahkan ke bahasa Arab. ${ }^{22}$ Ketua para penerjemah adalah Hunayn Bin Ishaq, seorang sarjana terbesar dan figur terhormat pada masanya. ${ }^{23}$ Salah satu penerjemah pertama dari bahasa Yunani adalah Abu Yahya Bin al-Bathriq (wafat antara tahun 796 M.-806 M.) yang dikenal karena menerjemahkan karya-karya Galen dan Hippocrates (w.436 S.M.) untuk al-Manshur dan karya Ptolemius, Quadripartitum untuk khalifah lainnya. ${ }^{24}$ Dalam menerjemahkan naskah-naskah, Khalifah al-Makmun menentukan penanggung jawab pada setiap bahasa sebagai pengawasan terhadap siapa yang menerjemahkan buku-buku kunonya, memberikan gaji kepada mereka di setiap bulannya sebesar 500 Dinar (setara dua kilo gram emas). ${ }^{25}$ Dengan mempelajari kitab-kitab Yunani Daulah Abbasiyah dapat membangun peradaban Islam yang agung dan membawa Islam mencapai masa keemasan khususnya bidang keilmuan, akan tetapi imperium ini runtuh pada awal abad ke-13 setelah terjadi perang antar saudara yang berlarut-larut, dan banyak pemberontakan yang terjadi. Pada permulaan Daulah Abbasiyah, pendidikan dan pengajaran berkembang pesat di seluruh negara islam sehingga lahir sekolah-sekolah yang tersebar di kota-kota sampai desa. Peradaban Islam megalami puncak kejayaan pada masa Daulah Abbasiyah. Perkembangan ilmu pengetahuan sangat maju. Selama pemerintahan al-Mutawakkil, di kota mereka berdiri sekolah filsafat dan kedokteran yang pada awalnya berada di Iskandariyah,

\footnotetext{
${ }^{22}$ Raghib al-Sirjani, Madza Qaddamal lil 'Alam Ishaamatu al-Muslimin fi al-Hadharah al-Insaniyah, terj. IKAPI, Sumbangan Peradaban Islam pada Dunia, h. 242.

${ }^{23}$ Philip K. Hitti, History of the Arabs; From the Earliest Times to the Present, terj. R. Cecep Lukman Yasin dan Dedi Slamet Riyadi, History of the Arabs, h. 388.

${ }^{24}$ Philip K. Hitti, History of the Arabs; From the Earliest Times to the Present, terj. R. Cecep Lukman Yasin dan Dedi Slamet Riyadi, History of the Arabs, h. 387.

${ }^{25}$ Raghib al-Sirjani, Madza Qaddamal lil 'Alam Ishaamatu al-Muslimin fi al-Hadharah al-Insaniyah, terj. IKAPI, Sumbangan Peradaban Islam pada Dunia, h. 242.
} 
kemudian dipindahkan ke Antiokia. ${ }^{26}$ Bukan saja membawa kemajuan di bidang ilmu pengetahuan umum, tetapi juga ilmu pengetahuan agama. Pada masa ini Ilmu dan metode tafsir mulai berkembang terutama dua metode penafsiran, yaitu tafsir bi al-ma'tsur dan tafsir bi al-ra'yi. Dalam bidang hadits mulai diklasifikasikan secara sistematis dan kronologis, sehingga kita kenal dengan klasifikasi hadits Shahih, Dhaif, dan Maudhu. Selain itu berkembang juga ilmu pengetahuan agama lain seperti ilmu Alquran, qira'at, fiqh, kalam, bahasa dan sastra. Empat mazhab fiqh tumbuh dan berkembang pada masa Abbasiyah ini Imam Abu Hanifah yang meninggal di Baghdad tahun 767 M. adalah pendiri madzab Hanafi. Imam Malik Bin Anas yang banyak menulis hadits dan pendiri Maliki itu wafat di Madinah pada tahun 796 M. Muhammad Bin Idris al-Shafi'i yang meninggal di Mesir tahun 819 M. adalah pendiri madzab Shafi'i, dan Ahmad Bin Hanbal pendiri madzhab Hanbali meninggal dunia tahun $855 \mathrm{M}^{27}$ Baghdad sebagai ibu kota kekhalifahan Abbasiyah yang didirikan oleh khalifah al-Mansur mencapai puncak kejayaan di masa al-Rasyid walau kota itu belum lima puluh tahun dibangun. Kemegahan dan kemakmuran tercermin dari istana khalifah, kemewahan istana muncul terutama dalam upacara-upacara penobatan khalifah, perkawinan, keberangkatan berhaji, dan jamuan untuk para duta negara asing. $^{28}$

Demikianlah kemajuan peradaban Islam pada masa Dinasti Abbasiyah. Selain apa yang diungkapkan terdahulu, masih banyak kemajuan-kemajuan dalam bidang lain, seperti bidang kedokteran, filsafat, sastra yang melahirkan ulamaulama terkemuka seperti Ibnu Sina, al-Kindi, al-Ghazali, al-Farabi, dan lain-lain.

\section{E. Kesimpulan}

Berdasarkan pemaparan-pemaparan sebelumnya dalam pembahasan ini, dapat ditarik kesimpulan sebagai berikut:

${ }^{26}$ Philip K. Hitti, History of the Arabs; From the Earliest Times to the Present, terj. R. Cecep Lukman Yasin dan Dedi Slamet Riyadi, History of the Arabs h. 391.

${ }^{27}$ Ali Mufrodi, Islam Di Kawasan Kebudayaan Arab (Jakarta: Logos Wacana Ilmu, 1997), h. 102

${ }^{28}$ Ali Mufrodi, Islam Di Kawasan Kebudayaan Arab, h. 104. 
Berdirinya Dinasti Abbasiyah sendiri tidak lepas dari runtuhnya Dinasti Umayyah. Dinasti Umayyah runtuh akibat permasalahan internal, yaitu tidak mapannya para khalifah dalam memimpin Dinasti Umayyah. Khalifah pada masa akhir Dinasti Umayyah hanya mementingkan kehidupan dunia tanpa memikirkan aturan agama. Hal ini menimbulkan kemarahan publik sehingga hal inipun dimanfaatkan oleh keturunan Bani Abbas untuk menarik simpati masyarakat dengan cara bergabung dengan kelompok pendukung Ali dan membesarkan nama mereka dengan menyatakan sebagai pembela Nabi dan agama. Dengan usaha ini pada akhirnya Dinasti Umayyah dapat diruntuhkan dan berdirilah Dinasti Abbasiyah

Masa kejayaan Dinasti Abbasiyah mencapai puncaknya pada pemerintahan Harun al-Rasyid (786-809 M.). Ilmu pengetahuan begitu berkembang, apalagi dengan gerakan penerjemahan naskah-naskah Yunani. Hal inipun pada akhirnya melahirkan para ulama-ulama handal, seperti al-Kindi, alFarabi, Ibnu Sina. Selain itu dibangun pula perpustakaan Baitul Hikmah pada masa Abu Ja'far al-Manshur sehingga ilmu pengetahuan berkembang pesat seperti filsafat, matematika dan sastra. Selain itu masih banyak lagi ilmu yang berkembang pada masa tersebut sehingga zaman ini disebut sebagai "The Golden Age”.

\section{Daftar Pustaka}

Amin, Ahmad. Dhuha al-Islam III : Kairo Mesir, al-Nahdhah al-Mishriyah, 1966.

Departemen Agama Republik Indonesia. Ensiklopedi Islam I. Jakarta: Ichtiar Baru Van Hoeve, 1997.

Gassing, A. Qadir. Pedoman Penulisan Karya Tulis Ilmiah. Makassar : Alauddin Press, 2013.

Husain Haekal, Muhammad. Utsman Bin Affan, terj. Ali Audah, Usman Bin Affan. Bogor: Pustaka Litera Antarnusa, 2010.

K. Hitti, Philip. History of the Arabs; From the Earliest Times to the Present, terj. R. Cecep Lukman Yasin dan Dedi Slamet Riyadi, History of the Arabs. Jakarta: PT. Serambi Ilmu Semesta, 2010. 
Mufrodi, Ali. Islam Di Kawasan Kebudayaan Arab. Jakarta: Logos Wacana Ilmu, 1997.

Surajio. Filsafat Ilmu dan Perkembangannya di Indonesia. Jakarta: PT. Bumi Aksara,2010.

Al-Shalabi, Ali Muhammad. Muawiyah Ibnu Abi Sufyan, terj. Izzuddin Karimi, Muawiyah Bin Abu Sufyan. Jakarta: Darul Haq, 2012.

Al-Sirjani, Raghib. Madza Qaddamal Muslimuna lil 'Alam Ishamaatu alMuslimin fi al-Hadharah al-Insaniyah. terj. IKAPI, Sumbangan Peradaban Islam Pada Dunia. Jakarta: Pustaka al-Kautsar, 2011.

Al-Suyuthi, Tarikh Khulafa', terj. Samson Rahman, Tarikh Khulafa': Sejarah Para Penguasa Islam. Jakarta : Pustaka al-Kautsar, 2011.

Al-Usairy, Ahmad. Al-Tarikh al-Islami, terj. Samson Rahman, Sejarah Islam. Jakarta: Akbar Media, 2012. 